\title{
STRENGTH AND STABILITY OF GOLD USING TWO BODY POTENTIALS
}

\author{
Vikram Singh \\ Physics Department, Agra College, Agra
}

\begin{abstract}
Numerical computations of strength and stability of Au in (100) loading mode of deformation are carried out by taking $K$. D. potential, Morse potential and $\mathrm{L}$ - J Potential. At failure points, second order elastic constants are also calculated. Computed results of K. D. potential are $6.99 \mathrm{GPa}$ at $7.76 \%$ of strain in tension and - 5.18GPa at $\mathbf{- 5 . 2 3 \%}$ of strain in compression. These results are fairly close with experimental results and computed results of other investigators.
\end{abstract}

Keywords : Strength, Stability, Two body potential, Stress, Strain.

\section{INTRODUCTION}

In principle, there is an upper limit to the mechanical strength of material under the given test conditions. This limit is termed as "ideal strength" or "theoretical strength" of the material. The ideal strength was originally defined as stress or strain at which perfect crystal lattice became mechanically unstable with respect to arbitrary homogeneous infinitesimal deformation. Many workers [1-32] have been calculated strength of cubic metals in various modes of deformations using different types of interaction between atoms. Using simulation technique, Cerney and coworkers [6-12] studied mechanical stability of cubic metals ( $\mathrm{Ni}, \mathrm{Ir}, \mathrm{Fe}, \mathrm{Cr}$ ) in hydrostatic loading and uniaxial loading. Ho et al [13] investigated the effect of transverse loading on ideal tensile strength of six FCC materials using molecular statics and density function theory. Review article on this topic is given by Ogata et al [14]. Zou et al [15] showed that a nano crystalline alloy retains an extra ordinary high yield strength over $5 \mathrm{GPa}$ up to $600^{\circ} \mathrm{C}$. Recently Ho et al [16] have investigated ideal strength of some FCC nano structures using MS simulation. Ideal strength of various $\mathrm{MC}(\mathrm{M}=\mathrm{Ti}, \mathrm{Zr}, \mathrm{Hf})$ systems using first principal calculations recently calculated by Yang et al [17]. Using EAM, many investigators [18-25] have been estimated strengths of cubic metals. Singh and coworkers [24, 25] recently calculated ideal strength of $\mathrm{Cu}$ and $\mathrm{Al}$ in (100) loading mode of deformation using analytic EAM. Using simulation techniques, Milstein et al [26, 27] have been calculated strength of many cubic metals. Using rigorous estimation of binding energy, Singh [28-30] and Mitra et al [31] estimated strength and stability of $\mathrm{Cu}, \mathrm{Ag}, \mathrm{Au}$ and $\mathrm{Al}$. These studies showed that in present time, the calculations of theoretical strength of cubic metals are an active field in research.

For calculations of mechanical properties of cubic metals, many two body potentials (such as Lennard Jones potential, Morse potential, logarithmic potential and K. D. potential) are used in literature. Milstein [32, 33] and Mitra et al [34] calculated theoretical strength of $\mathrm{Fe}, \mathrm{Ni}$ and $\mathrm{Al}$ using Morse potential. Singh [35-37] estimated strength and stability of $\mathrm{Cu}$ and $\mathrm{Al}$ using $\mathrm{K}$. D. potential in different modes of deformation. These results are fairly close with experimental results. Using K. D. potential as an interaction between atoms, recently Singh et al [38-40] have calculated second order elastic constants, third order elastic constants and pressure derivatives of second order elastic constants of many FCC metals and found that the calculated results are very close with experimental results. As per our knowledge the calculation of strength of Gold using two body potentials are not present in literature. So this give me a motivation to calculate theoretical strength of Gold taking different types of two body potential as an interaction between atoms. In this study, the first section gives present status of work, second section gives computation details of two body potentials and (100) loading mode of deformation, third section gives results and discussion of work, fourth section gives conclusions of work and last fifth section gives the reference of the work.

\section{COMPUTATIONAL DETAIL}

\subsection{TWO BODY POTENTIALS}

In this study we are using three two body potentials (K. D. potential, Morse potential and Lennard Jones 
12-6 potential). Two body potential as suggested by Kuchhal and Dass [41] is given as

$$
\phi(r)=-A r^{-n}+B \exp \left(-p r^{m}\right)
$$

Where $\mathrm{m}$ and $\mathrm{n}$ are two adjustable parameters and $\mathrm{A}$, $\mathrm{B}$ and $\mathrm{p}$ are unknown potential parameters which are expressed in the unit of erg.cm ${ }^{\mathrm{n}}$, erg and $\mathrm{cm}^{-\mathrm{m}}$ respectively. Singh et al [40] have calculated these parameters by taking experimental values of lattice parameter, bulk modulus and cohesive energy as an input data. These unknown potential parameters for Gold are shown in table 1.

Morse potential function is given as

$$
\phi(r)=D\left(e^{-2 \alpha\left(r-r_{0}\right)}-2 e^{-\alpha\left(r-r_{0}\right)}\right)
$$

$\mathrm{D}, \alpha$ and $\mathrm{r}_{0}$ are three unknown potential parameters which are determined by many workers for different cubic metals using some physical quantities as an input data. As per our knowledge, Morse potential parameters for Gold are estimated by Flahive et al [42] and Milstein [43]. These parameters are shown in table 1.

Lennard - Jones 12-6 ( $\mathrm{L}$ - J) potential function is given as

$$
\phi(r)=4 \varepsilon\left[\left(\frac{\sigma}{r}\right)^{12}-\left(\frac{\sigma}{r}\right)^{6}\right]
$$

This potential contains only two unknown parameters. As per our knowledge, these parameters are calculated by Halicioglu et al [44] and Zhen et al [45] for Gold, which are shown in table 1. In all these equations $r$ gives the distance from a lattice site chosen as the origin to a given lattice site with coordinate specified by the three integers $l_{1} . l_{2}, l_{3}$ as

$$
r=\frac{1}{2}\left(a_{1}^{2} l_{1}^{2}+a_{2}^{2} l_{2}^{2}+a_{3}^{2} l_{3}^{2}\right)^{\frac{1}{2}}
$$

Where $l_{1}, l_{2}$ and $l_{3}$ are integers (chosen such that $l_{1}+l_{2}$ $+l_{3}$ is even for an FCC lattice) and $a_{1}, a_{2}$, and $a_{3}$ are cell lengths. (In equilibrium the lattice parameters $\mathrm{a}_{1}$ $=\mathrm{a}_{2}=\mathrm{a}_{3}=4.0783(\AA)$ for Gold [45])

\subsection{THEORY OF (100) LOADING}

Detailed theory has been given by Milstein [32, 33] for applying Born stability criteria to the determination of mechanical stability of cubic crystals in the presence of applied forces and deformations. For uniaxial stress in cubic crystals with central interactions, the necessary and sufficient conditions for a lattice to be in stable equilibrium are

$$
\begin{gathered}
B_{12}>0 \\
B_{23}>0 \\
B_{22}-B_{23}>0 \\
B_{11}\left(B_{22}+B_{23}\right)-2 B_{12}^{2}>0
\end{gathered}
$$

For brevity of notation we represent $B_{22}-B_{23}>0$ by ab1 and $B_{11}\left(B_{22}+B_{23}\right)-2 B_{12}^{2}>0$ by ab2. Stress $\sigma_{\mathrm{i}}$ is being given by

$$
\sigma_{i}=\frac{1}{a_{j} a_{k}}\left(\frac{\partial E}{\partial a_{i}}\right)=\frac{u a_{i}}{4 a_{j} a_{k}} \sum_{l_{1}} \sum_{l_{2}} \sum_{l_{3}} l_{i}^{2} \frac{\partial \phi}{\partial r^{2}}
$$

Where $\mathrm{E}$ is the energy per unit cell

$$
E=\frac{u}{2} \sum_{l_{1}} \sum_{l_{2}} \sum_{l_{3}} \phi(r)
$$

$\mathrm{B}_{\mathrm{ij}}$ are given by

$$
\begin{aligned}
B_{i j}=\left(\frac{\partial^{2} E}{\partial a_{i} \partial a_{j}}\right) & =\frac{u a_{i} a_{j}}{8} \sum_{l_{1}} \sum_{l_{2}} \sum_{l_{3}} l_{i}^{2} l_{j}^{2} \frac{\partial^{2} \phi}{\left(\partial r^{2}\right)^{2}} \\
& +\frac{u}{4} \delta_{i j} \sum_{l_{1}} \sum_{l_{2}} \sum_{l_{3}} l_{i}^{2} \frac{\partial \phi}{\partial r^{2}}
\end{aligned}
$$

for $i, j=1,2,3$

Where $\delta_{\mathrm{ij}}$ is the Kronecker delta function and $\mathrm{u}$ is the number of atoms per unit cell. The summations are carried out over a number of atoms sufficiently large to ensure that convergence up to four significant figures is achieved. In case of (100) loading, increase or decrease the lattice parameter $a_{1}$ and the lattice parameters $\mathrm{a}_{2}=\mathrm{a}_{3}$ are allowed to change symmetrically such that the deformed lattice maintains the tetragonal symmetry. This method developed by Milstein [32, 33] and calculated theoretical strength of $\mathrm{Fe}$ and $\mathrm{Ni}$ in this mode of deformation using Morse potential function as an interaction between atoms. 
International Journal of Engineering Applied Sciences and Technology, 2020

Vol. 5, Issue 4, ISSN No. 2455-2143, Pages 390-398

Published Online August 2020 in IJEAST (http://www.ijeast.com)

\begin{tabular}{|c|c|c|c|c|c|c|}
\hline \multicolumn{7}{|c|}{ K. D. potential [40] } \\
\hline $\mathrm{m}$ & $\mathrm{n}$ & \multicolumn{2}{|c|}{$\mathrm{p}\left(\mathrm{cm}^{-1}\right)$} & \multicolumn{2}{|c|}{$\mathrm{A}\left(\mathrm{erg}-\mathrm{cm}^{\mathrm{n}}\right)$} & B (erg) \\
\hline 1 & $1 / 2$ & \multicolumn{2}{|c|}{$3.04 \times 10^{9}$} & \multicolumn{2}{|c|}{$1.1508 \times 10^{-18}$} & $6.9101 \times 10^{23}$ \\
\hline 2 & 1 & \multicolumn{2}{|c|}{$2.728 \times 10^{16}$} & \multicolumn{2}{|c|}{$4.8686 \times 10^{-22}$} & $1.6332 \times 10^{-4}$ \\
\hline 1 & 2 & \multicolumn{2}{|c|}{$7.89 \times 10^{8}$} & \multicolumn{2}{|c|}{$7.4295 \times 10^{-29}$} & $7.463 \times 10^{-4}$ \\
\hline \multicolumn{3}{|c|}{ Morse potential } & \multicolumn{2}{|c|}{$\mathrm{D}\left(10^{-12} \mathrm{erg}\right)$} & $\alpha\left(\AA^{-1}\right)$ & $r_{0}(\AA)$ \\
\hline \multicolumn{3}{|c|}{ Flahive et al [ 42] } & \multicolumn{2}{|c|}{.773222} & 1.6166 & 3.004 \\
\hline \multicolumn{3}{|c|}{ Milstein [43] } & \multicolumn{2}{|c|}{1.44487} & .476645 & 5.9845 \\
\hline \multicolumn{4}{|c|}{ Lennard Jones potential } & \multicolumn{2}{|l|}{$\varepsilon / \mathrm{K}$} & $\sigma(\AA)$ \\
\hline \multicolumn{4}{|c|}{ Halicioglu et al [44] } & \multicolumn{2}{|l|}{5123} & 2.637 \\
\hline \multicolumn{4}{|c|}{ Zhen et al [45] } & \multicolumn{2}{|c|}{5152.9} & 2.6367 \\
\hline
\end{tabular}

Table 1 Potential parameters of two body potentials for Gold.

\section{CALCULATIONS, RESULTS AND DISCUSSION}

Figures from 1 to 4 show the variations of $B_{i j}$, ab1, $\mathrm{ab} 2$, lattice parameter $\mathrm{a}_{2}$, stress $\sigma_{1}$ and energy per unit cell (E) with respect to lattice parameter $\mathrm{a}_{1}$ for K. D. potential (for $\mathrm{m}=1$ and $\mathrm{n}=1 / 2$ ). Similarly the variations of $\mathrm{B}_{\mathrm{ij}}, \mathrm{ab} 1, \mathrm{ab} 2$, lattice parameter $\mathrm{a}_{2}$, stress $\sigma_{1}$ and energy per unit cell (E) with lattice parameter $\mathrm{a}_{1}$ in case of Morse potential (Flahive et al [42]) and Lennard Jones potential (Halicioglu et al [44]) as an interaction between atoms are shown in figures from 5 to 12 . The variations of these quantities for other potentials (K. D. potential for other values of adjustable parameters, Morse potential which parameters are calculated by Milstein [43] and Lennard Jones potential which parameters are calculated by Zhen et al [45]) are not shown here since the nature of these plots are approximately similar. Thus in this study we are giving only computed results for these potentials.

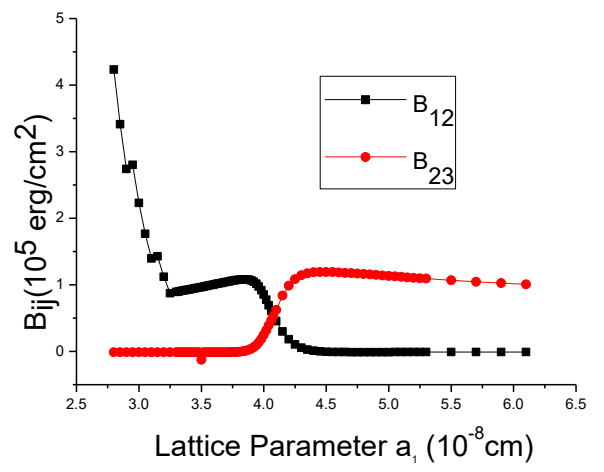

Figure 1 Variation of $B_{i j}$ with lattice parameter $a_{1}$.

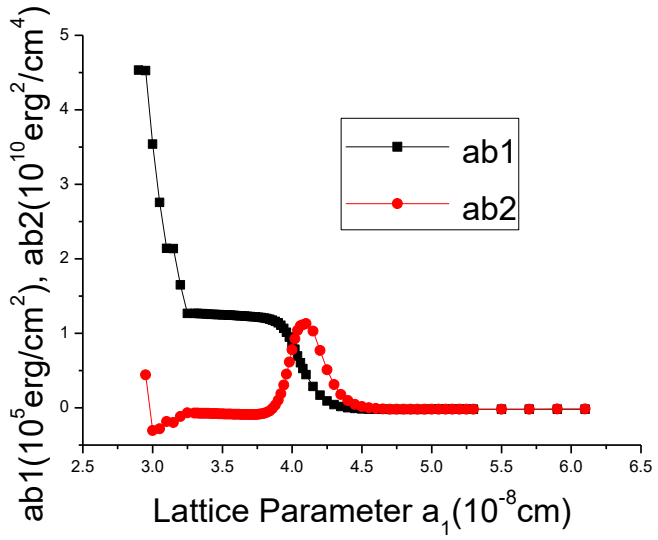

Figure 2 Variation of $a b 1$ and $a b 2$ with lattice parameter $\mathrm{a}_{1}$.

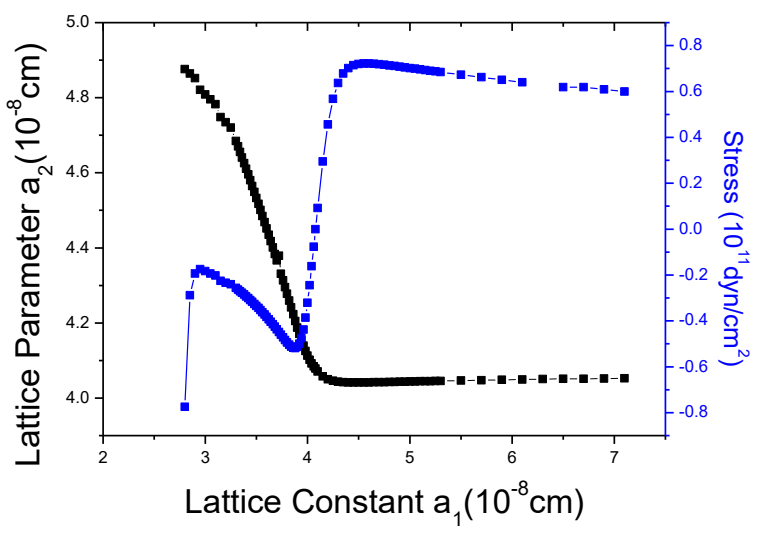

Figure 3 Variation of lattice parameter $\mathrm{a}_{2}$ and stress $\sigma_{1}$ with lattice parameter $\mathrm{a}_{1}$. 


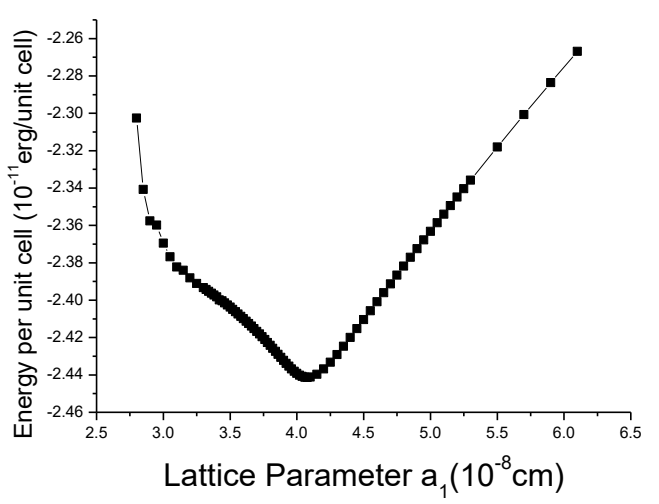

Figure 4 Variation of energy per unit cell (E) with lattice parameter $\mathrm{a}_{1}$.

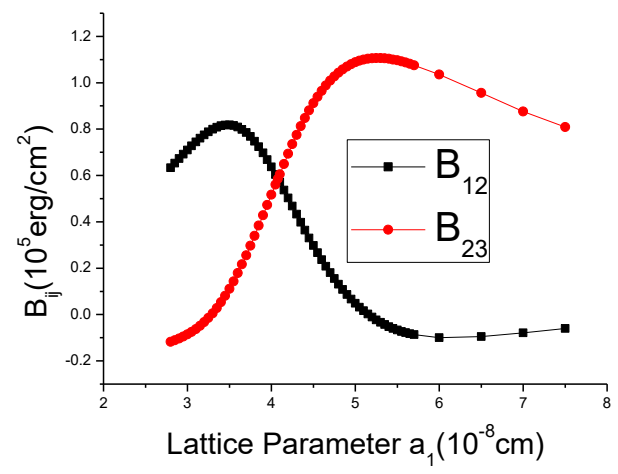

Figure 5 Variation of $\mathrm{B}_{\mathrm{ij}}$ with lattice parameter $\mathrm{a}_{1}$ for Morse potential.

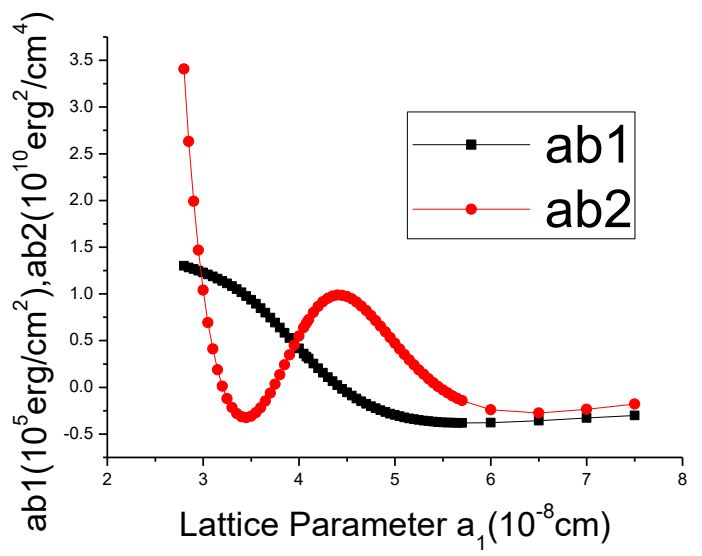

Figure 6 Variation of ab1 and ab2 with lattice parameter $\mathrm{a}_{1}$ for Morse potential.

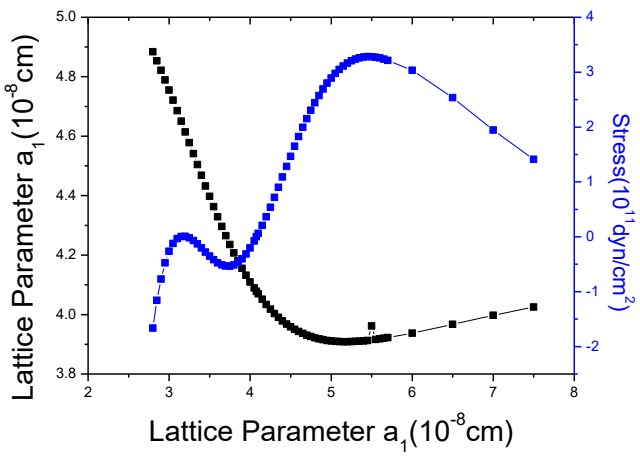

Figure 7 Variation of lattice parameter $\mathrm{a}_{2}$ and stress $\sigma_{1}$ with lattice parameter $a_{1}$ for Morse potential.

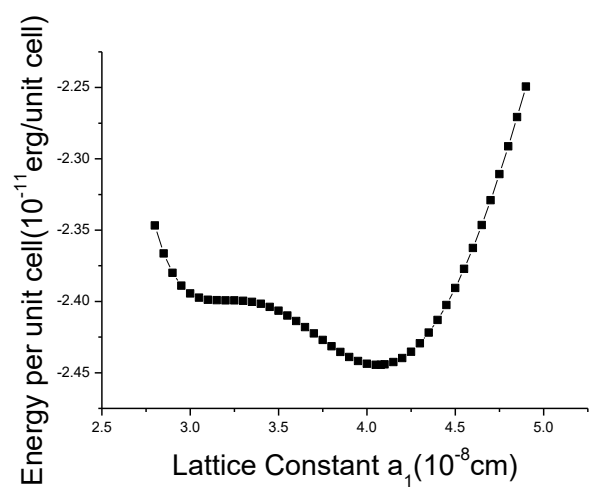

Figure 8 Variation of energy per unit cell (E) with lattice parameter $\mathrm{a}_{1}$ for Morse potential

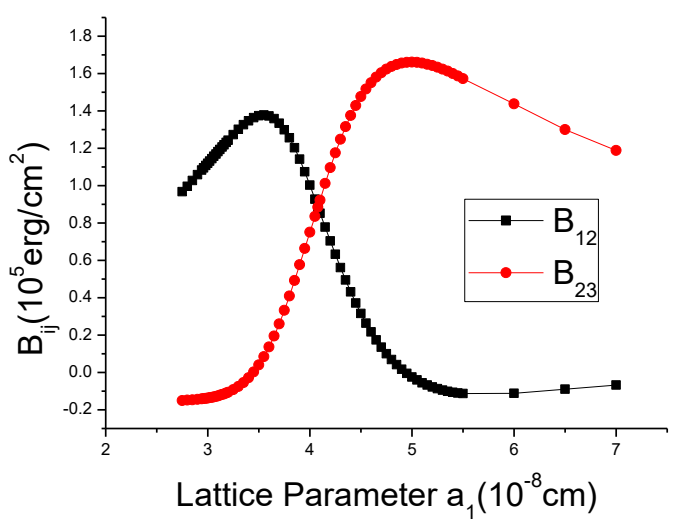

Figure 9 Variation of $B_{i j}$ with lattice parameter $a_{1}$ for Lennard Jones potential. 


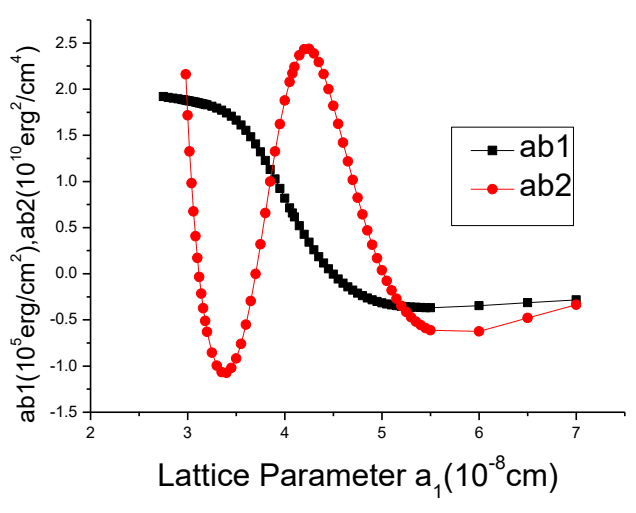

Figure 10 Variation of $a b 1$ and ab2 with lattice parameter $\mathrm{a}_{1}$ for Lennard Jones potential.

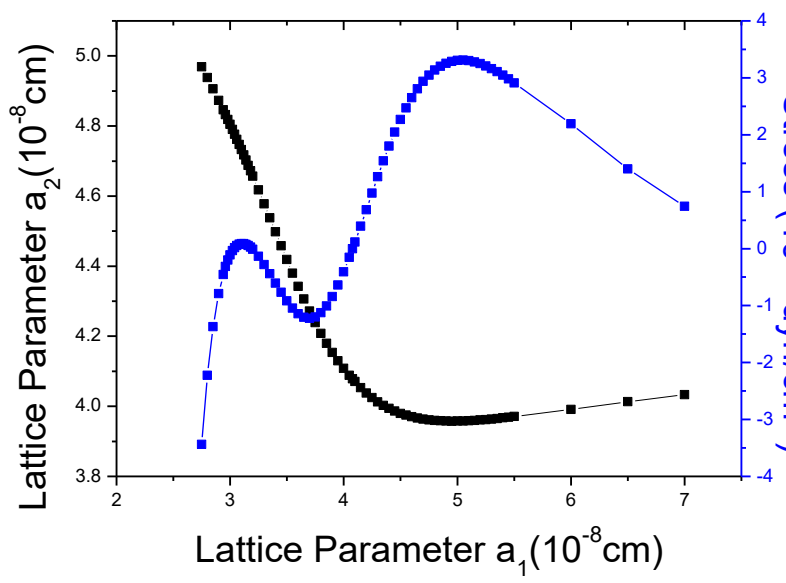

Figure 11 Variation of lattice parameter $\mathrm{a}_{2}$ and stress $\sigma_{1}$ with lattice parameter $a_{1}$ for Lennard Jones potential.

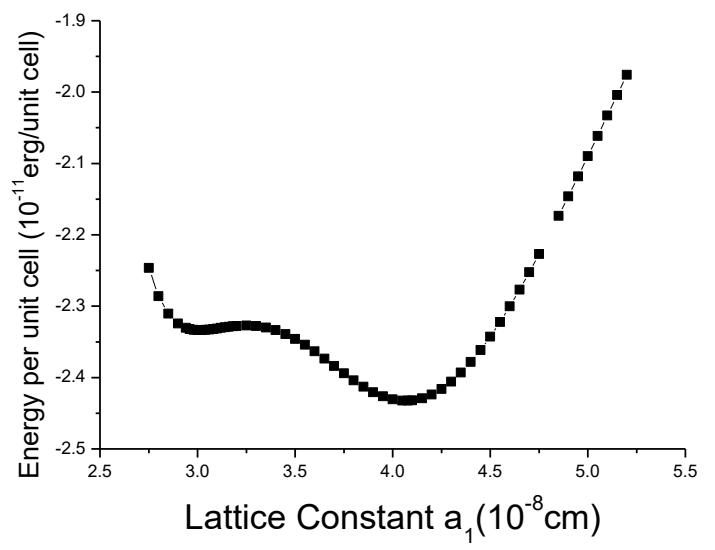

Figure 12 Variation of energy per unit cell (E) with lattice parameter $\mathrm{a}_{1}$ for Lennard Jones potential.

In case of $K$. D. potential, in compression the stability condition $\mathrm{ab} 2$ is violated at $\mathrm{a}_{1}=3.865(\AA)$ and in tension stability condition ab1 is violated at $\mathrm{a}_{1}$ $=4.395(\AA)$. Breaking stresses at these points are 6.99GPa in tension and $-5.18 \mathrm{GPa}$ in compression. These values of stresses and strains (which is equal to $\left(a_{1}^{c}-a_{1}^{0}\right) / a_{0}$ where $a_{1}^{c}$ is lattice constant $\left(\mathrm{a}_{1}\right)$ at which Born stability criteria violated) give strength and stability of Gold. Thus tensile strength is $6.99 \mathrm{GPa}$ at $7.76 \%$ of strain and compressive strength is $-5.18 \mathrm{GPa}$ at $5.23 \%$ of strain. In tension, stress reaches its maximum value $7.219 \mathrm{GPa}$ at $\mathrm{a}_{1}=4.55(\AA)$. During compression stress reaches maximum values $1.75 \mathrm{GPa}$ at $\mathrm{a}_{1}=3.1(\AA)$ but the energy per unit cell is not reaches local maximum or minimum values. At these points the values of lattice constant $a_{2}$, energy per unit cell and second order elastic constants $\mathrm{C}_{11}$ $\oiiint$ and $\mathrm{C}_{12}$ are shown in table 2. Table 2 also gives theoretical strength of Gold at different values of adjustable parameters $\mathrm{m}$ and $\mathrm{n}$ in K. D. potential.

For Morse potential [42], the stability condition ab2 is violated at $\mathrm{a}_{1}=3.7334(\AA)$ in compression and stability condition ab1 is violated at $\mathrm{a}_{1}=4.4279(\AA)$ in tension and the breaking stresses at these points are $11.98 \mathrm{GPa}$ in tension and $-5.37 \mathrm{GPa}$ in compression. Thus theoretical strength of Au using Morse potential is $11.98 \mathrm{GPa}$ at $8.57 \%$ of strain in tension and $5.137 \mathrm{GPa}$ at $-8.46 \%$ of strain in compression. In tension, stress reaches its maximum value $32.813 \mathrm{GPa}$ at $\mathrm{a}_{1}=5.45(\AA)$. At these points the values of lattice constant $\mathrm{a}_{2}$, stress and second order elastic constants $\mathrm{C}_{11}$ and $\mathrm{C}_{12}$ are shown in table 3 . We also calculated strength of Gold using Morse potential whose parameters are calculated by Milstein [43]. Computed results of theoretical strength of Gold by taking this Morse potential are also summarized in table 3. The stability condition $\mathrm{B}_{23}$ is violated instead of ab2 during compression in this Morse potential. During compression, we calculate $\mathrm{B}_{\mathrm{ij}}$, ab1, ab2, stress and energy per unit cell up to $a_{1}=2.5(\AA)$ but in this potential the stress is not reaches its maximum value similarly the energy per unit cell also not reaches its maximum and minimum value which is found in Flahive [43] potential.

Similarly, the stability condition ab2 is violated at $a_{1}$ $=3.7014(\AA)$ in compression and stability condition ab1 is violated at $\mathrm{a}_{1}=4.495(\AA)$ in tension for Lennard Jones potential. Breaking stresses at these points are $22.5 \mathrm{GPa}$ in tension and $-12.25 \mathrm{GPa}$ in compression. Thus the theoretical strength of Gold 
using Lennard Jones $12-6$ potential is $22.5 \mathrm{GPa}$ at $10.22 \%$ of strain in tension and $-12.25 \mathrm{GPa}$ at $-9.24 \%$ of strain in compression. Maximum value of stress is 33.099GPa at $\mathrm{a}_{1}=5.05(\AA)$ in tension. At these points the values of lattice constant $\mathrm{a}_{2}$, stress and second order elastic constants $\mathrm{C}_{11}$ and $\mathrm{C}_{12}$ are shown in table 4. We also calculate theoretical strength of Gold by taking another $\mathrm{L} \mathrm{J}$ potential which is developed by Zhen et al [45] and are given in table 4 . The results of these two potential are approximately similar.

Figures 4,8 and 12 show that when lattice constant $\mathrm{a}_{1}$ varies from equilibrium value, the other lattice constants $a_{2}$ and $a_{3}$ also varies in such manner the crystal remains in the state of uniaxial stress. Throughout this deformation, lattice parameter $\mathrm{a}_{2}$ decreases as $a_{1}$ increases but for larger values of $a_{1}, a_{2}$ increases as $a_{1}$ increases. The same results are found by Milstein [33] for Ni. In this study the stress in compression reaches it maximum value (negative in $\mathrm{K}$. D. potential and positive in Morse and L - J potential) and then further decreases as decrease the lattice parameter $a_{1}$. Energy per unit cell has also local maxima and minima during compression in Morse and $\mathrm{L}$ - $\mathrm{J}$ types of interaction between atoms. These results show second unstable phase during compression and this is detailed explained by Milstein [33] for FCC metals. However, in K. D. potential local maxima and minima of energy per unit cell is absent during compression but the stress still reaches maximum value and this show second unstable phase during compression.

\begin{tabular}{|c|c|c|c|c|c|c|}
\hline \multirow[t]{2}{*}{ Potentials } & \multirow[t]{2}{*}{$\mathrm{a}_{1}(\AA)$} & \multirow[t]{2}{*}{$\mathrm{a}_{2}(\AA)$} & \multirow[t]{2}{*}{$\begin{array}{l}\sigma_{1} \\
(\mathrm{GPa})\end{array}$} & \multicolumn{2}{|c|}{$\begin{array}{l}\text { Second order elastic } \\
\text { constants }\left(10^{12} \mathrm{dyn} / \mathrm{cm}^{2}\right)\end{array}$} & \multirow[t]{2}{*}{$\begin{array}{l}\text { Cause of failure or maximum } \\
\text { stress }\end{array}$} \\
\hline & & & & $\mathrm{C}_{11}$ & $\mathrm{C}_{12}$ & \\
\hline \multirow{5}{*}{$\begin{array}{l}\text { K. D. } \\
\text { potential } \\
\mathrm{m}=1 \\
\mathrm{n}=1 / 2\end{array}$} & 4.395 & 4.0418 & 6.99 & .116 & .0322 & Failure in tension $(\mathrm{ab} 1=0)$ \\
\hline & 4.0783 & 4.0783 & 0 & 2.5918 & 1.3034 & At equilibrium [40] \\
\hline & 3.865 & 4.218 & -5.18 & 4.236 & 2.561 & Failure in compression $(\mathrm{ab} 2=0)$ \\
\hline & 4.55 & 4.0414 & 7.219 & - & - & Maximum stress in tension \\
\hline & 2.95 & 4.8211 & -1.75 & - & - & Maximum stress in compression \\
\hline \multirow{5}{*}{$\begin{array}{l}\text { K. D. } \\
\text { potential } \\
\mathrm{m}=1 \\
\mathrm{n}=2\end{array}$} & 4.6129 & 3.9837 & 17.16 & .756 & .236 & Failure in tension $(\mathrm{ab} 1=0)$ \\
\hline & 4.0783 & 4.0783 & 0 & 2.5205 & 1.3381 & At equilibrium [40] \\
\hline & 3.6397 & 4.318 & -43.18 & 2.694 & 2.131 & Failure in compression $(\mathrm{ab} 2=0)$ \\
\hline & 5.1 & 3.978 & 20.647 & - & - & Maximum stress in tension \\
\hline & 3.1 & 4.7333 & -4.959 & - & - & Maximum stress in compression \\
\hline \multirow{5}{*}{$\begin{array}{l}\text { K. D. } \\
\text { potential } \\
\mathrm{m}=2 \text {, } \\
\mathrm{n}=1\end{array}$} & 4.539 & 4.0165 & 11.835 & .265 & .0722 & Failure in tension $(\mathrm{ab} 1=0)$ \\
\hline & 4.0783 & 4.0783 & 0 & 2.5774 & 1.3104 & At equilibrium [40] \\
\hline & 3.7837 & 4.261 & -8.46 & 2.459 & 1.643 & Failure in compression $(\mathrm{ab} 2=0)$ \\
\hline & 4.8 & 4.0159 & 12.549 & - & - & Maximum stress in tension \\
\hline & 3.07 & 4.864 & -3.898 & - & - & Maximum stress in compression \\
\hline
\end{tabular}

Table 2 Computed results at different values of adjustable parameters $m$ and $n$ in K. D. potential.

\begin{tabular}{|c|c|c|c|c|c|c|}
\hline \multirow[t]{2}{*}{ Potentials } & \multirow[t]{2}{*}{$\mathrm{a}_{1}(\AA)$} & \multirow[t]{2}{*}{$\mathrm{a}_{2}(\AA)$} & \multirow[t]{2}{*}{$\begin{array}{l}\sigma_{1} \\
(\mathrm{GPa})\end{array}$} & \multicolumn{2}{|c|}{ 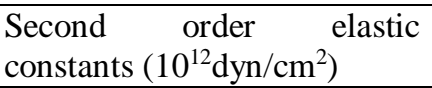 } & \multirow[t]{2}{*}{$\begin{array}{l}\text { Cause of failure or maximum } \\
\text { stress }\end{array}$} \\
\hline & & & & $\mathrm{C}_{11}$ & $\mathrm{C}_{12}$ & \\
\hline \multirow{8}{*}{$\begin{array}{l}\text { Flahive et } \\
\text { al [42] }\end{array}$} & 4.4279 & 3.973 & 11.98 & 1.978 & .876 & Failure in tension $(\mathrm{ab} 1=0)$ \\
\hline & 4.0783 & 4.0783 & 0 & 2.2433 & 1.435 & At equilibrium \\
\hline & 3.7334 & 4.245 & -5.37 & 1.95 & 1.826 & Failure in compression $(\mathrm{ab} 2=0)$ \\
\hline & 5.45 & 3.9129 & 32.813 & & & Maximum stress in tension \\
\hline & 3.2 & 4.6141 & .072 & & & Maximum stress in compression \\
\hline & 3.14 & 4.652 & 0 & & & \multirow{2}{*}{$\begin{array}{l}\text { During compression, the region } \\
\text { where stress is positive }\end{array}$} \\
\hline & 3.22 & 4.6 & 0 & & & \\
\hline & 3.225 & 4.598 & 0 & & & Minimum energy in compression \\
\hline Milstein & 4.5339 & 3.928 & 16.78 & 2.821 & 1.25 & Failure in tension $(\mathrm{ab} 1=0)$ \\
\hline
\end{tabular}


International Journal of Engineering Applied Sciences and Technology, 2020

Vol. 5, Issue 4, ISSN No. 2455-2143, Pages 390-398

Published Online August 2020 in IJEAST (http://www.ijeast.com)

\begin{tabular}{|l|l|l|l|l|l|l|}
\hline$[43]$ & 4.0783 & 4.0783 & 0 & 2.512 & 1.791 & At equilibrium \\
\cline { 2 - 6 } & 3.012 & 4.7 & -42.7 & 6.136 & 1.809 & Failure in compression $\left(\mathrm{B}_{23}=0\right)$ \\
\cline { 2 - 6 } & 7.4 & 4.0017 & 136.357 & & & Maximum stress in tension \\
\cline { 2 - 5 } & \multicolumn{6}{|l|}{ Maximum stress in compression is not found } \\
\cline { 2 - 5 } & \multicolumn{7}{l}{ Minimum energy in compression is not found } \\
\end{tabular}

Table 3 Computed results for Morse potential [42, 43]

\begin{tabular}{|c|c|c|c|c|c|c|}
\hline \multirow[t]{2}{*}{ Potentials } & \multirow[t]{2}{*}{$\mathrm{a}_{1}(\AA)$} & \multirow[t]{2}{*}{$\overline{a_{2}(\stackrel{\AA}{ })}$} & \multirow[t]{2}{*}{$\begin{array}{l}\sigma_{1} \\
(\mathrm{GPa})\end{array}$} & \multicolumn{2}{|c|}{$\begin{array}{l}\text { Second order elastic } \\
\text { constants }\left(10^{12} \mathrm{dyn} / \mathrm{cm}^{2}\right)\end{array}$} & \multirow[t]{2}{*}{$\begin{array}{l}\text { Cause of failure or maximum } \\
\text { stress }\end{array}$} \\
\hline & & & & $\mathrm{C}_{11}$ & $\mathrm{C}_{12}$ & \\
\hline \multirow{8}{*}{$\begin{array}{l}\text { Hilicioglu } \\
\text { et al [44] }\end{array}$} & 4.495 & 3.98 & 22.5 & 1.978 & .809 & Failure in tension $(\mathrm{ab} 1=0)$ \\
\hline & 4.0783 & 4.0783 & 0 & 3.7768 & 2.1673 & At equilibrium \\
\hline & 3.7014 & 4.27 & -12.25 & 3.7686 & 3.1384 & Failure in compression $(\mathrm{ab} 2=0)$ \\
\hline & 5.05 & 3.9581 & 33.099 & & & Maximum stress in tension \\
\hline & 3.1 & 4.7323 & .864 & & & Maximum stress in compression \\
\hline & 3.03 & 4.783 & 0 & & & \multirow{2}{*}{$\begin{array}{l}\text { During compression the region } \\
\text { where stress is positive }\end{array}$} \\
\hline & 3.19 & 4.669 & 0 & & & \\
\hline & 3.01 & 4.7975 & -.68 & & & Minimum energy in compression \\
\hline \multirow{8}{*}{$\begin{array}{l}\text { Zhen et al } \\
\text { [45] }\end{array}$} & 4.495 & 3.98 & 22.5 & 1.97 & .809 & Failure in tension $(\mathrm{ab} 1=0)$ \\
\hline & 4.0783 & 4.0783 & 0 & 3.79 & 2.1752 & At equilibrium \\
\hline & 3.7018 & 4.27 & -12.25 & 3.766 & 3.136 & Failure in compression $\left(\mathrm{B}_{23}=0\right)$ \\
\hline & 5.05 & 3.9582 & 33.186 & & & Maximum stress in tension \\
\hline & 3.1 & 4.7333 & .944 & & & Maximum stress in compression \\
\hline & 3.03 & 4.79 & 0 & & & \multirow{2}{*}{$\begin{array}{l}\text { During compression the region } \\
\text { where stress is positive }\end{array}$} \\
\hline & 3.199 & 4.659 & 0 & & & \\
\hline & 3.01 & 4.799 & -.655 & & & Minimum energy in compression \\
\hline
\end{tabular}

Table 3 Computed results for $\mathrm{L} \mathrm{J}$ potential $[44,45]$

Many other investigators $[19,20,23,30]$ also calculated theoretical strength of Gold. Using rigorous estimation of binding energy Singh [30] has calculated strength of Gold and found $2.312 \mathrm{GPa}$ at $2.4 \%$ of strain in tension and $-1.35 \mathrm{Gpa}$ at $-1.75 \%$ of strain. Using EAM Cifitci et al [19], Milstein et al [20] and Zhang et al [23] calculated tensile strength of Gold and found 3.173GPa, 10GPa and 6.31GPa respectively. Ho [13] and Cerny et al [46] also estimated strength of Gold and found 4.09GPa and $7 \mathrm{GPa}$ respectively. Experimental values of strength of Gold whiskers are .784GPa [47] and 1.156GPa [48] which is less than of our calculated results. Tensile strength of whiskers, which usually do not appear to be perfect crystals, is quite low. It has been reported by Neugebauer [47] and confirmed by Blakely [48]. Thus our computed results of strength using K. D. potential are same order in magnitude of experimental and calculated results of other workers. However the computed results of Morse and L - J potential are 2 to 3 times higher than the computed results of other investigators.

\section{CONCLUSIONS}

As per our knowledge no one calculated theoretical strength of Gold using two body potentials. Many workers estimated strength of Gold using EAM, simulation techniques and pseudo potential approach. As we know that the calculations with two body potentials are simple and they are also used in simulation techniques so the estimation of mechanical properties using two body potentials are also important. Our computed results show that the estimated strength of Gold is fairly match with experimental results and computed results of other investigators. For all potentials, the nature of variations of lattice parameter $a_{2}$, stress and energy per unit cell with $a_{1}$ are same. Second order elastic constants at failure points are also calculated which are not reported by other worker except Singh [30]. This study also show that the two body potential which is used and developed by Kuchhal and Dass 
gives better results in comparison to Morse and $\mathrm{L}-\mathrm{J}$ potential.

\section{ACKNOWLEDGEMENT}

The author is thankful to Dr. Gitam Singh, of R. B. S. College, Agra for their valuable discussion and moral support and Dr. Gaurang Misra of physics department Agra College, Agra for his stimulating encouragement and helping hand for typing related problems.

\section{REFERENCES}

1. Clatterbuck D. M., Chrzan D. C. and Morris Jr. Scrip. Mater., 49 (2003) 1007.

2. Clatterbuck D. M., Chrzan D. C. and Morris Jr. Phil. Mag. Lett. 82 (2002) 141.

3. Friak M., Šb M. and Vitek V. Phil. Mag. 83 (2003) 3529.

4. Tschopp M. A. and McDowell D. L. Appl. Phys. Lett. 90 (2007) 121916.

5. Tschopp M. A. and McDowell D. L. J. Mech. Phys. Solids 56 (2008) 1806.

6. Cerny M. and Pokluda J. Journal of Alloys and Compound 378 (2004) 159.

7. Cerny M. Material Science and Engineering: A, 4621 (2007) 432.

8. Cerny M., Sastak P., Pokluda J. and So Phys. Rev. B 87 (2013) 014117.

9. Rehak P. and Cerney M. Engineering Materials, 592-593 (2014) 547.

10. Rehak P. and Cerney M. Modelling and Simul. in Mater. Sci. and Eng. 23 (2015).

11. Černy M., Pokluda J., Šob M., Friak M. and Šandera P. Phys. Rev. B 67 (2003) 035116.

12. Černy M., Šandera P., and Pokluda J. Czech. J. Phys. 49 (1999) 1495.

13. Ho D. T., Park S. D., Kwon S. Y., Han T. S. and Kim S. Y. Euro. Physics Letters, 111 (2015) 26005.

14. Ogata S., Umeno Y. and Kohyama M. Modelling and Simul. in Scie. and Eng. 17 (2009).

15. Zou Yu., Jeffrey M., Wheeler, Huan Ma, Philipp Okle, and Ralph Spolenak, Phys. Nano Lett., January (2017).

16. Duc Tam Ho, Soon Kim, Soon-Yong Kwon and Sung Youb Kim., Mechanics materials, 141 (2020) 103241.

17. Bo Yang, Xianghe Peng, Henggo Xiang, Deqiang Yin, Cheng Huang, Sha Sun, Tao $\mathrm{Fu}$, J. Alloys and compounds, 739 (2018) 431.

18. Cai J. Phys. Status Solid. B 203 (1997) 345.
19. Özteken Ciftci Y. and Colakogeu K. Acta Physica Polanica A 100 (2001) 539.

20. Zhang J. M., Yang Y., Xu K. W. and Ji V. Compt. Mater. Sci. 43 (2008) 917.

21. Zhang J. M., Lin Z. L., Zhang Y. and Ji V. Pramana J. of Phys. 742 (2010) 261.

22. Milstein F. and Chantasiriwan S. Phys. Rev. B 58 (1998) 6006.

23. Vikram Singh and Gitam Singh, Research and Review: Jour. of Phys. 5(3) (2016) 28.

24. Vikram Singh and Sharma B. K. International journal of Sci. Res. in Phys. and Appl. Sci. 8(2) (2020) 06.

25. Milstein F., Zhao J. and Maroudas D. Phys. Rev. B 70 (2004) 184102.

26. Milstein F., Zhao J., Chantasiriwan S. and Maroudas D. Appl. Phys. Letter 87 (2005) 251919.

27. Singh G. Ind. Jour. of Pure and Applied Phys. 28 (1990) 122.

28. Singh G. Phys. Stat. Sol. (b) 161 (1990) 145.

29. Singh G. Phys. Stat. Sol. (b), 164 (1991) 401.

30. Mitra A. K. and Sengupta P. K. J. Phys. (F) Met. Phys. 13 (1983) 2221.

31. Milstein F. Phys. Rev. B 3(4) (1971) 1130.

32. Milstein F. J. of Appl. Phys. 44(9) (1973) 3833.

33. Mitra A. K. and Sengupta P. K. Ind. J. Pure and Appl. Phys. 18 (1980) 205.

34. Vikram Singh IJSER 4(10) (2016) 117.

35. Vikram Singh Advance Physics Letter 3(4) (2016) 13.

36. Vikram Singh Deliberative Research 17(2) (2013) 01.

37. Vikram Singh and Sharma B. K. Journal of Pure Applied and Industrial Phys. 10(4) (2020) 01.

38. Vikram Singh and Sharma B. K. IJSRD 8(2) (2020) 377.

39. Vikram Singh and Sharma B. K. IRJET 7(4) (2020) 2656.

40. Kuchhal P. and Dass N. S. Pramana J. of phys. 53 (1999) 783.

41. Flahive P. G. and Graham W. R. Surf. Sci. 91 (1980) 449.

42. Milstein F. J. of Appl. Phys. 44(9) (1973) 3825 .

43. Halicioglu T. and Pound G. M. Phys. Stat. Soli. (b) 30 (1975) 619.

44. Zhen S. and Davies G. J. Phys. Stat. Soli. (a) 78 (1983) 595.

45. C. Kittel, Introduction to solid state physics (John Wiley, New York) (1971). 
International Journal of Engineering Applied Sciences and Technology, 2020

Vol. 5, Issue 4, ISSN No. 2455-2143, Pages 390-398

Published Online August 2020 in IJEAST (http://www.ijeast.com)

46. Cerny M. and Pokluda J. J. Phys. Cond. Matt. 21 (2009) 145406.

47. Neugebauer C. A. J. Appl. Phys. 31 (1960) 1096.

48. Blakely J. M. J. Appl. Phys. 35 (1964) 7656. 